to fight the kill with the aid of Greenpeace and their boat Rainbow Warrier. Sue Flint provides an insight into the events that led up to the local confrontation and the successful plans which eventually foiled the hunters. The book does not present an emotional stand, but pleads for a more informed basis for decisions involving thousands of animals whose ecology is very little understood. The real reasons for opposing the kill were not well known by the general public, and Sue Flint redresses the balance in her very readable account. It is no mean tribute to Selkie and Greenpeace that there was no further kill in 1979 and that the Government has been forced to examine the so-called management plan and consultation procedures with voluntary wildlife bodies.

SUSAN JOY

\title{
The Evolution of the Mammals by L.B. Halstead. Peter Lowe, $£ 4.50$.
}

Although essentially an illustrated book and obviously intended for the general reader, this volume is thorough and comprehensive, and the text is concise. The final chapters are of particular interest, dealing with the Pleistocene and post-Pleistocene extinctions, and the last chapter, 'The Future', is an eloquent 'plug' for conservation - an interesting innovation for a book on fossils. The illustrations were specially commissioned from 13 artists; all are pleasing and seem accurate, and a few are outstanding. At $£ 4.50$ a first-rate purchase for anyone with even a passing interest in either palaeontology or conservation.

JOHN A. BURTON

\section{My Wilderness Wildcats, by Mike Tomies. Macdonald and Janes, £5.95.}

The reader's attention is captured in the first paragraph of this attractively written book with the introduction of two wildcat kittens - ready to fight for their immature lives with all the ferocity that characterises their kind. The story of these kittens, Cleo and Patra, reared with sympathy for their untamable natures, is enhanced by the description of the author's wilderness home in the Highlands of Scotland. The introduction of a ten-year-old tom, which had lived most of its life in isolation at London Zoo and was uncompromisingly wild, and the mating with one of the two young females bring out many of the usual aspects of these wild mammals. Gradually all the cats are given the freedom of the forest, their movements checked by the author and his Alsatian dog. There is pathos in the discovery of a dead wildcat which might be one of the family, but satisfaction at the end when each cat is traced. Illustrated by the author's photographs, this book is enjoyable, packed with information and more exciting than Watership Down because it is a true story.

VERA N. PAUL

Though not written in a popular style, Professor David Spence's Shetland's Living Landscape: a study in island plant ecology (Thule Press, Sandwick, Shetland, 16.50) will be invaluable to any visitors to the Shetlands interested in the flora, vegetation and landscape, and their interrelations. A Shetlander himself, he has devoted a lifetime to careful analysis of the plant communities of the archipelago.

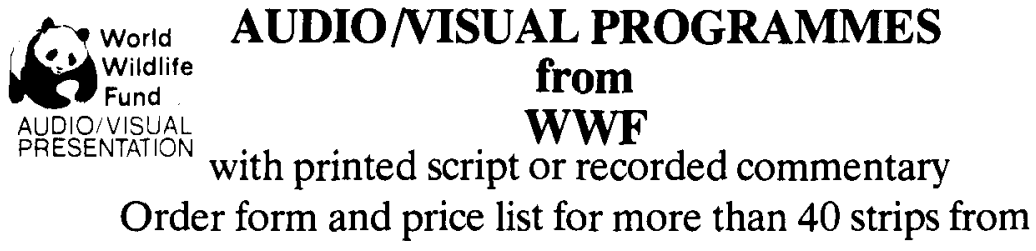

WWF Education Project 1180

Greenfield House, Guiting Tower, Gloucestershire 